\title{
Onychomycosis in patients with diabetes mellitus: Etiology, clinical features, and treatment response
}

\author{
Alma Ileana Molina-Hernandez', Hassiel Aurelio Ramírez-Marín', Alexandro Bonifaz², \\ Judith Guadalupe Dominguez-Cherit ${ }^{1}$
}

\author{
${ }^{1}$ Dermatology Department, Instituto Nacional de Ciencias Médicas y Nutrición "Salvador Zubirán”, Mexico City. Mexico, \\ ${ }^{2}$ Mycology Department, Hospital General de México "Dr. Eduardo Liceaga”, Mexico City, México
}

Corresponding author: Judith Guadalupe Dominguez-Cherit M.D, E-mail: Dominguez.judith@gmail.com

\begin{abstract}
Background: Onychomycosis accounts for 30\% of all superficial mycoses and $50 \%$ of all nail diseases. One of the most studied predisposing factors is diabetes mellitus, with a frequency of onychomycosis of $31.5 \%$ in these patients. Many show resistance to standard therapeutics and have "polypharmacy", which represents a risk for pharmacological interactions. Objective: The objective was to assess the clinical response to therapy, evaluate with histopathology, direct examination with $\mathrm{KOH}$ and white-calcofluor, and culture the most frequent etiologic agents associated with the development of onychomycosis in patients with diabetes mellitus. Materials and Methods: A non-randomized, uncontrolled, open-ended, prospective cohort study was conducted on 46 patients with onychomycosis and diabetes mellitus. Treatment was assigned according to clinical findings and specific indications for treatment. Results: From the samples taken for direct examination with $\mathrm{KOH}$ and calcofluor-white, culture, and histopathological study, positive results were: $39(84.1 \%)$ patients to the direct examination, $32(69.6 \%)$ to the culture, $27(65.2 \%)$ with a positive histopathological study, and $17(54.86 \%)$ to the calcofluor-white. On clinical evaluation, we found no treatment response in 8 patients (20\%), a partial response in 14 patients (25\%), and a complete response in 18 patients $(45 \%)$. Out of the 46 patients evaluated initially, 25 persisted with onychomycosis after six months of follow-up. Conclusion: The prevalence of onychomycosis is increasing and requires correct diagnosis since there are other non-fungal diseases of the nails that resemble onychomycosis. Presumably, the immunosuppression of diabetes, its systemic affection, and the foot abnormalities of a diabetic patient cause more nail dystrophy, an increased fungal load, and treatment resistance.
\end{abstract}

Key words: onychomycosis; diabetes mellitus; mycoses; dermatophytes; non-dermatophytes molds; nails; immunosuppression; fungi; polypharmacy

\section{INTRODUCTION}

Onychomycosis affects $5.5 \%$ of the general population [1] and accounts for $30 \%$ of all superficial mycoses and $50 \%$ of all nail diseases $[2,3]$. The estimated prevalence is over $10 \%$ in the general population and about $40 \%$ in older adults [2]. The main causative agents of onychomycosis are dermatophytes; however, in those that do not respond to standard therapeutics, non-dermatophyte molds should be considered associated or causal agents [2].
One of the most studied predisposing factors is diabetes mellitus, with a frequency of onychomycosis of $31.5 \%$ in these patients $[2,4]$. It is now accepted that diabetes increases the relative risk of developing onychomycosis (from 1.5 to 2.8 times) compared to non-diabetic patients [2]. In a study on 400 patients in India, the prevalence of onychomycosis in diabetics was found to be $17 \%$, being $6.8 \%$ in the control group [4]. Other factors related to an increased incidence of onychomycosis include old age, male sex, repeated nail traumas, genetic predisposition and underlying diseases

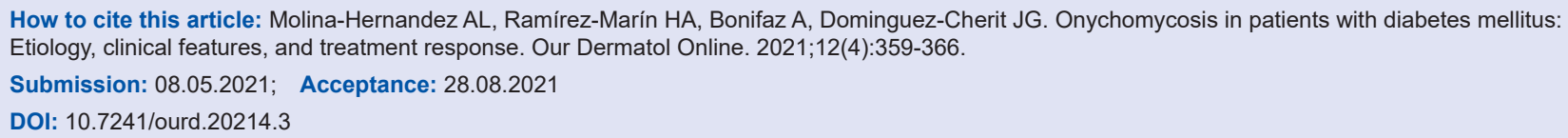


such as immunodeficiency, and peripheral vascular disease [4]. Nail thickness has been positively associated with higher $\mathrm{HbAlC}$ levels [5], accelerating the typical subungual keratinization induced by fungal infection. Fungal infections exceed $50 \%$ of all types of infections among diabetic patients [6]. Diabetic patients with onychomycosis exhibit a higher percentage of gangrene and foot ulcers $(12.2 \%)$ compared to those without onychomycosis $(3.8 \%)$ [7,8].

Onychomycosis represents a risk for the development of the diabetic foot due its association with difficulty in nail clipping, causing the patient to injure themselves, producing an access route for bacterial agents [9]. Many of these patients show resistance to standard therapeutics (in some cases associated with incomplete previous treatments); they also have "polypharmacy," which represents a risk of pharmacological interactions in systemic management, or have contraindications for systemic management, hence they are candidates for topical treatment, after culture.

This study aimed to assess the clinical response to therapy and to evaluate with histopathology, direct examination with $\mathrm{KOH}$ and white-calcofluor, and culture the most frequent etiologic agents associated with the development of onychomycosis in patients with diabetes mellitus, both susceptible and resistant to standard treatment.

\section{MATERIALS AND METHODS}

A non-randomized, uncontrolled, open-ended, prospective cohort study was conducted on 46 patients with onychomycosis and diabetes mellitus treated at the Instituto Nacional de Ciencias Médicas y Nutrición "Salvador Zubirán," regardless of the time of evolution. Treatment was assigned according to clinical findings and specific indications for treatment, according to the type of onychomycosis and the number of affected nails (Table 1 ).

All patients were treated after their first dermatology evaluation with a follow-up at three months (in the case of systemic treatment) and at six months (in the case of topical treatment). Nails were photographed for follow-up and the samples were taken for direct examination with $\mathrm{KOH} 10 \%$ and calcofluor-white, and for mycological culture with agar for dermatophytes, SDA and potato dextrose agar. Furthermore, the distal edge of one of the affected nails was cut for histopathological study. Treatment adherence
Table 1: Treatment assigned according to clinical findings and specific indications according to the type of onychomycosis and the number of affected nails

\begin{tabular}{|c|c|}
\hline $\begin{array}{l}\text { Terbinafine } 250 \mathrm{mg} \text { every } 24 \\
\text { hours for } 3 \text { months }\end{array}$ & $\begin{array}{l}\text { Patients with the indication of systemic } \\
\text { treatment without liver failure, creatinine } \\
\text { clearance greater than } 50 \mathrm{ml} / \mathrm{min} \text { or those } \\
\text { who had no interacting drugs. }\end{array}$ \\
\hline $\begin{array}{l}\text { Itraconazole } 200 \mathrm{mg} \text { every } \\
24 \text { hours for } 3 \text { months }\end{array}$ & $\begin{array}{l}\text { Patients with the indication of systemic } \\
\text { treatment, without liver failure, with or } \\
\text { without renal failure, or those who had no } \\
\text { interacting drugs. }\end{array}$ \\
\hline $\begin{array}{l}\text { Fluconazole } 150 \mathrm{mg} \text { every } 7 \\
\text { days, for } 3 \text { months }\end{array}$ & $\begin{array}{l}\text { Patients with the indication of systemic } \\
\text { treatment, with superficial white } \\
\text { onychomycosis. }\end{array}$ \\
\hline $\begin{array}{l}\text { Urea } 40 \% \text { and bifonazole } 2 \% \\
\text { topical }\end{array}$ & $\begin{array}{l}\text { Patients with the indication of topical } \\
\text { treatment, who presented subungual } \\
\text { hyperkeratosis or those who had } \\
\text { contraindications for systemic treatment. }\end{array}$ \\
\hline Amorolfine lacquer & $\begin{array}{l}\text { Patients with the indication of topical } \\
\text { treatment, without subungual hyperkeratosis. }\end{array}$ \\
\hline
\end{tabular}

evaluation was conducted by interrogation during patient evaluations.

\section{Ethics Statement}

The authors confirm that the ethical policies of the journal, as noted on the journal's author guidelines page, were adhered to and the appropriate ethical review committee approval was received.

\section{RESULTS}

46 patients with diabetes and a clinical suspicion of onychomycosis were evaluated, 24 males (52.2\%) and 22 females (47.8\%), with an age ranging from 30 to 90 years, with a median of 57 . Two patients were eliminated from the final analysis for death, and no sample was obtained for study from four other patients as they were lost on the last consultation.

Among the patients evaluated, a total of 25 (54.3\%) were clinically found with distal subungual onychomycosis, $29(63 \%)$ with total dystrophic onychomycosis, $2(4.3 \%)$ with superficial white onychomycosis, $4(8.7 \%)$ with lateral subungual onychomycosis, among whom the most affected finger was the first left toe, with $41.3 \%$.

Among the treatments indicated, 2 received itraconazole $200 \mathrm{mg}$ daily (4.3\%), 7 received itraconazole in pulses, 13 received oral terbinafine daily (30.4\%), 2 applied amorolfine lacquer, and 15 were treated with topical bifonazole at $2 \%$ plus urea $40 \%$ (37.5\%). We found global healing of $73 \%$, with topical management with urea $40 \%$ + bifonazole, and a response of $9 \%$ with 
systemic terbinafine, $17 \%$ with itraconazole in pulses, and $50 \%$ with itraconazole daily (Table 2 ).

All nails at follow-up were photographed. Samples were taken for direct examination with $\mathrm{KOH}$ and calcofluor-white, culture and histopathological study. The positive results were: $39(84.1 \%)$ patients to direct examination, $32(69.6 \%)$ to culture, $27(65.2 \%)$ with positive histopathological study, and 17 (54.86\%) with calcofluor-white. At the end of the study, the patients underwent a new clinical evaluation and new samples were taken for direct examination with $\mathrm{KOH}$ and calcofluor-white, culture, and histopathological study. Positive results were found in 10 patients $(25 \%)$ with direct examination, 18 (45\%) patients with positive culture, and 20 patients (54.28\%) with positive histopathology.

Table 2: Treatment and mycological cure in patients with onychomycosis and diabetes mellitus

\begin{tabular}{|c|c|c|c|c|c|c|}
\hline \multirow[t]{3}{*}{ Treatment } & \multicolumn{4}{|c|}{ Mycological Cure } & \multicolumn{2}{|c|}{ Total } \\
\hline & \multicolumn{2}{|c|}{ Yes } & \multicolumn{2}{|c|}{ No } & \multirow[b]{2}{*}{ No. } & \multirow[b]{2}{*}{$\%$} \\
\hline & No. & $\%$ & No. & $\%$ & & \\
\hline Terbinafine & 1 & 9 & 10 & 91 & 11 & 100 \\
\hline Terbinafine + urea and bifonazole & 0 & 0 & 2 & 100 & 2 & 100 \\
\hline Itraconazole pulses & 1 & 17 & 5 & 83 & 6 & 100 \\
\hline $\begin{array}{l}\text { Itraconazole pulses + urea and } \\
\text { bifonazole }\end{array}$ & 1 & 100 & 0 & 0 & 1 & 100 \\
\hline Itraconazole 200 mg daily & 1 & 50 & 1 & 50 & 2 & 100 \\
\hline Urea + Bifonazol & 11 & 73 & 4 & 27 & 15 & 100 \\
\hline Cyclopyrroxolamine lacquer & 1 & 100 & 0 & 0 & 1 & 100 \\
\hline Amorolfine lacquer & 0 & 0 & 2 & 100 & 2 & 100 \\
\hline Total & 16 & 40 & 24 & 60 & 40 & 100 \\
\hline
\end{tabular}

The most frequent histopathological findings before treatment were as follows: compact keratin (93\%), parakeratosis (88\%), septate short filaments (63\%), and bacterial colonies (45\%). In biopsies after treatment with positive results, parakeratosis was found in $95 \%$, other frequent findings were septate short filaments (18\%), serum (48\%), and bacterial colonies (60\%) (Table 3) (Fig. 1).

In 40 patients evaluated at the end of the study, 2 showed no treatment adherence (5\%), 9 patients $(22.5 \%)$ showed $50 \%$ adherence, and 29 patients $(72.5 \%)$ showed $100 \%$ adherence. It was considered $100 \%$ adherence in those who applied their treatment from the beginning, $50 \%$ in those who began the treatment late and $0 \%$ in those who failed to begin the treatment. Greater adherence was found in patients with systemic treatment (17 of the $29 ; 58.62 \%$ ), compared to 13 patients with topical treatment (13 of the 29; 44.82).

Four patients received systemic treatment, with a minimum of one month of treatment (late onset) and a maximum of five months (prolonged treatment to clinical cure), with a median of 3; and among the 18 patients with topical treatment, the minimum treatment duration observed was two months and the maximum was six months, with a median of four; with a patient with indicated topical treatment which was not initiated. On clinical evaluation, we found no response in 8 patients (20\%), a partial response in 14 patients (25\%), and a complete response in 18 patients (45\%) out

Table 3: Histopathological findings at the beginning and end of the study in nail biopsies of patients with onychomycosis and diabetes mellitus

\begin{tabular}{|c|c|c|c|c|c|c|c|c|}
\hline \multirow[t]{2}{*}{ Before Treatment } & \multirow[t]{2}{*}{$\mathbf{N}$} & \multirow[t]{2}{*}{$\%$} & \multirow[t]{2}{*}{ Histopathological Finding } & \multicolumn{2}{|c|}{ Before Treatment } & & \multicolumn{2}{|c|}{ After Treatment } \\
\hline & & & & $\mathbf{N}$ & $\%$ & & $\mathbf{N}$ & $\%$ \\
\hline \multirow[t]{16}{*}{ Positive } & 28 & 70 & Compact keratin & 37 & 93 & Positive & 38 & 95 \\
\hline & & & Melanic pigment & & & $17(42 \%)$ & 1 & 3 \\
\hline & & & Hematoma in the stratum corneum & & & & 1 & 3 \\
\hline & & & Parakeratosis & 35 & 88 & & 37 & 93 \\
\hline & & & Septate short filaments & 25 & 63 & & 7 & 18 \\
\hline & & & Non-septate short filaments & & & & 1 & 3 \\
\hline & & & Gram-positive cocci bacteria & 18 & 45 & & 24 & 60 \\
\hline & & & Serum & 13 & 33 & & 19 & 48 \\
\hline & & & Microabscesses of neutrophils & 4 & 10 & & 8 & 20 \\
\hline & & & Arthrospores & 3 & 8 & & 2 & 5 \\
\hline & & & Pseudohyphae & 2 & 5 & & & \\
\hline & & & Laminar keratin & 2 & 5 & & & \\
\hline & & & Septate filaments, thick or long & 2 & 5 & & 3 & 8 \\
\hline & & & Yeast & 1 & 3 & & 4 & 10 \\
\hline & & & Branched and angled septate filaments at $15-40^{\circ}$ & & & & 8 & 20 \\
\hline & & & Septate short filaments with vesicular dilatations & & & & 4 & 10 \\
\hline Negative & 12 & 30 & & & & $23(58 \%)$ & & \\
\hline Total & 40 & 100 & & & & 40 (100\%) & & \\
\hline
\end{tabular}




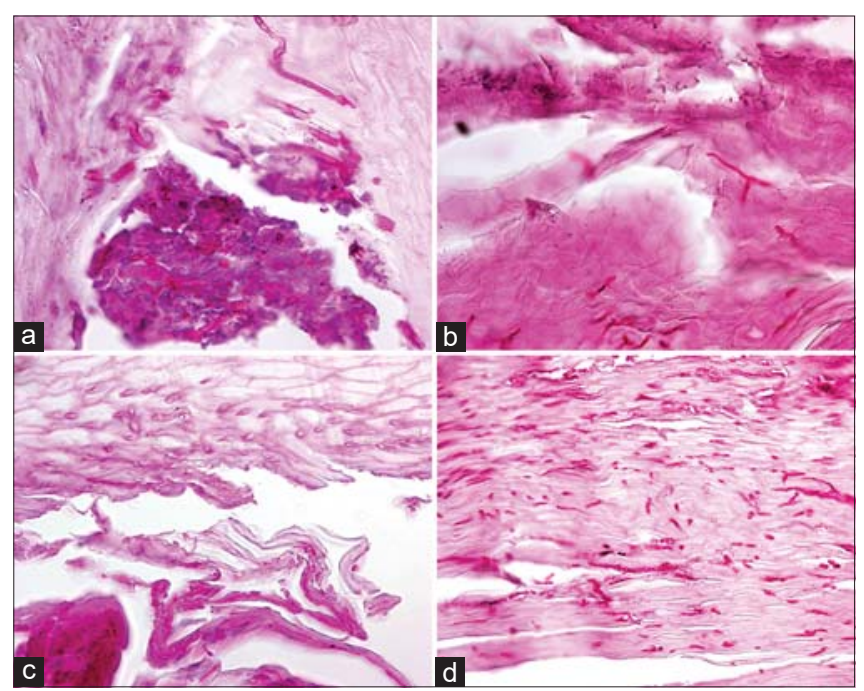

Figure 1: (a) Compact keratin sheets associated with bacterial colonies, septate filaments. (b) Compact keratin sheets associated with bacterial colonies, septate and angled filaments. (c) Compact keratin sheets and thick filaments. (d) Compact keratin sheets associated with bacterial colonies, spores, hyphae, and pseudohyphae.

of the total of 40 patients evaluated. Finally, considering the clinic, and the control studies by histopathological study, direct examination, and culture, it was found that, out of the 46 patients evaluated initially, 25 persisted with onychomycosis. Among these, a late onset of treatment was found in 13 patients, and among the causes evaluated, 11 patients reported economic causes, 1 apathy, and 1 gastrointestinal alterations, such as heartburn, after the beginning of systemic treatment.

Considering the patients who completed their treatment in a consistent manner, completing the minimum treatment required for systemic (three months) or topical (six months) treatment and who, with or without clinical resolution, continued with positive diagnostic studies (direct examination, culture, or histopathological study), 4 (10\%) were considered resistant to conventional treatment, without being able to consider the remaining 21 within this group, since they had not completed the indicated treatment by the late onset of the same.

\section{DISCUSSION}

Onychomycosis in diabetics is more than just a cosmetic problem and may be a limb-threatening infection if managed inappropriately [7]. A prospective study of 1285 diabetic patients found that the presence of onychomycosis is a significant predictor for the development of foot ulcers [8]. Onychomycosis in diabetic patients is more frequently observed in the presence of poor glycemic control and peripheral vascular disease [10]. A study found that the presence of onychomycosis in patients with diabetes is associated with subclinical atherosclerosis, which in diabetic patients represents the leading cause of death. [11]. The thickened, brittle nails typical of this infection are capable of causing damage to the surrounding skin that may go unnoticed due to coexistent neuropathy. Enlarged, dystrophic toenails may also put increased pressure on the underlying toe, compromising its tenuous vascular supply and causing pressure ulcers $[11,12]$. The pressure required to clip thickened toenails may cause inadvertent damage to the surrounding skin. If the patient is unable to perform appropriate foot hygiene, overgrowth of thickened toenails may cause damage to the surrounding skin as well. The subungual debris typical of distal subungual onychomycosis may become a reservoir for molds and bacteria $[11,13]$, which may represent potential invaders of the compromised skin barrier. According to the Achilles Foot Screening Project, the most commonly clinically diagnosed foot diseases in the total population of patients who visited a dermatologist were fungal infections (35\%), especially onychomycosis $(23 \%)$ and tinea pedis (22\%) [14]. Its etiology includes dermatophytes, yeasts, and fungi, in order of frequency. Regarding this, in a retrospective study lasting for 14 years on onychomycosis by molds, conducted at the Hospital General de Mexico by Bonifaz et al. [15], it was found that the most frequent clinical presentation was lateral and distal subungual in $69 \%$ of the cases, with Scopulariopsis brevicaulis in 34/78 patients and Aspergillus niger in $13 / 78$ (16.6\%) of the patients studied [15] Mixed infections and those caused by non-dermatophyte molds are more prevalent than previously thought, especially in warmer climates [16].

The results found in this study are consistent with the rest of the literature, since most of the patients presented total dystrophic onychomycosis, followed by distal subungual onychomycosis, and the most affected finger was the first of the left foot, with $41.3 \%$.

Dermatophytic onychomycosis, predominates in male patients in a relation of $2: 1$. The global prevalence falls between $2-15 \%$ in adults and represents $50 \%$ of all ungual conditions [12].

Indications for systemic treatment include having three or more affected nail plates or having the condition on one nail at the level of the nail matrix [15]. The main difference in treatment is due to the fact that 
some of the patients have chronic renal disease with creatinine clearance less than $50 \mathrm{ml} / \mathrm{min}$, which contraindicates the use of terbinafine. Although it is the safest drug with the fewest drug interactions, there are no controlled studies in patients with creatinine clearance below $50 \mathrm{ml} / \mathrm{min}$. For these, itraconazole may be used safely, although most of our population has polypharmacy, which sometimes makes management difficult because of drug interactions. It also requires greater vigilance with baseline and follow-up liver function tests.

Direct examination is performed after adding potassium hydroxide $(\mathrm{KOH})$. KOH preparations have been reported to have a false-negativity rate of 5-15\% [15]. Direct examination with $\mathrm{KOH}$, although operator-dependent, correlates with culture results and with the number of positive histopathological studies, the latter being the gold standard in the diagnosis of onychomycosis, and further supports the positivity of cultures and rules out their contamination. Fungi may be better visualized by adding chlorazol black, periodic acid-Schiff (PAS), or calcofluor-white stain [17]. The use of the latter significantly increases the sensitivity and specificity of this technique for the detection of dermatophytes, yeasts, and non-dermatophyte fungi [18].

Among the main limitations of the study was the lack of confirmation through molecular biology studies, due to the lack of equipment in the institute. One of the key difficulties in interpreting this study is that the majority of fungi identified by culture are either not known to be nail pathogens or are highly rare pathogens. Despite diminution of immunity in some diabetics, the pathogens cited, such as Fusarium, cause onychomycosis in the face of profound neutropenia, which is rather different from that in diabetics. Another explanation might be that a dermatophyte in the nail has not grown due to the presence of contaminating fungi. Another is that the fungi found are secondary to some other cause of onychodystrophy.

The presence of bacterial clusters is interesting. It might be due to space under the nail, and the growth of bacteria such as $S$. aureus, which is key to the development of diabetic ulcers, is favored.

The increase in the number of histopathological findings in the control biopsies is thought to have been due to the fact that, initially, some of the patients were managed by "podiatrists," and, in addition to having been treated with bad nail cutting, they were given excessive filing of the nails, which made it difficult for some patients to take samples from their nails. When taking control samples, filing and cutting were intentionally suspended for a week prior to the evaluation for facilitation.

Diagnosis of onychomycosis is difficult because of the difficulty in isolating fungi from infected nails. The classical technique is performed with a curette. However, Shemer et al. showed in a study on 194 patients that, with a technique in which a channel $1-2 \mathrm{~mm}$ in size is perforated with an ungual drill, a medial, distal, and proximal sample can be taken, being effective for culture and therefore for diagnosis [19] (Fig. 2). Nail sampling is, in fact, a delicate procedure that requires the mycelium front to be reached by the instrument in order to provide positive cultures [20,21]. Histopathology of nail clippings stained with PAS also referred to as histomycology with PAS is the most sensitive method of diagnosing onychomycosis [22], while others point out that it is not more effective than direct examination [23,24]. Confocal laser-scanning microscopy is an emerging diagnostic technique. The aspect of dermatophytes appears as a network of lengthy structures with high reflection and the typical shape of hyphae $[25,26]$. Other interesting new tools in the diagnosis of onychomycosis are the dermatophyte test strip and Raman spectroscopy [22].

Immunosuppressed patients show variation in clinical presentation, as well as in causative agents. Additionally, fungi traditionally considered as non-pathogenic may be found as pathogens, often associated with high mortality, as in the case of Fusarium species that cause perionyxis and may provide a gateway for a disseminated infection [27]. As for the isolated agents in the cultures for this study, a large number of opportunistic fungi was found (Acremonium sp. Candida sp. (Fig. 3), Alternaria sp. Aureobasidium sp., Aspergillus sp., Candida guilliermondi, Candida albicans, Rhodotorula sp., Cryptococcus albidus

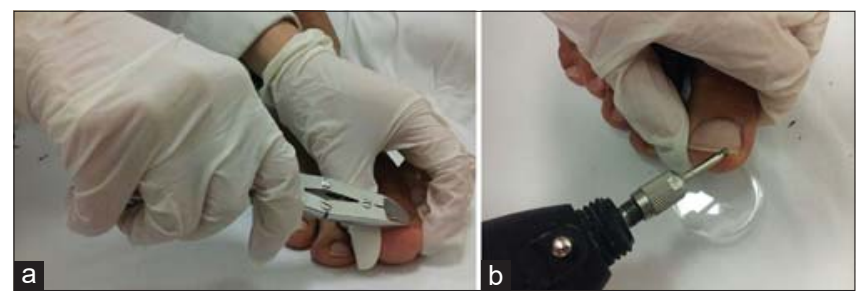

Figure 2: (a) Nail cutting technique for histopathological study. (b) The technique to obtain the sample with a drill for direct examination with $\mathrm{KOH}$, calcofluor white, and culture. 


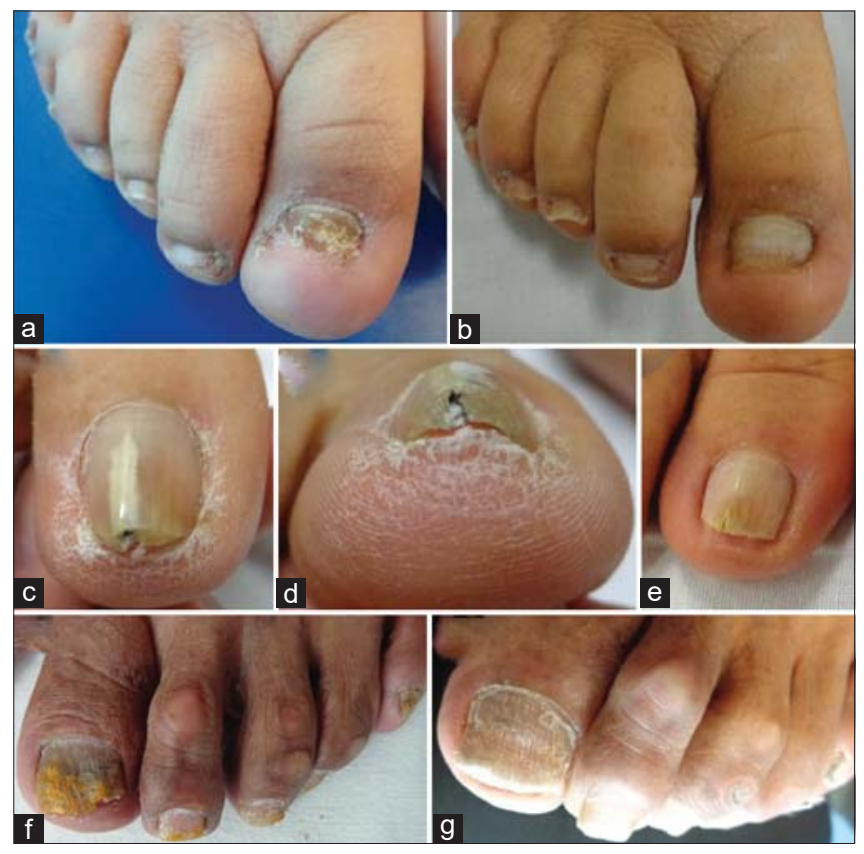

Figure 3: (a-b) Candida parapsilopsis. Positive on direct examination and culture. (a) Initial photograph with total dystrophic onychomycosis. (b) Final photograph after six months of topical treatment with $40 \%$ urea and bifonazole. Clinical and mycological cure. (c-e) Acremonium sp., Candida sp. Positive direct examination and histopathological study. (c-d) Initial photograph. (e) Final photograph after six months of topical treatment with $40 \%$ urea and bifonazole. Clinical and mycological cure. (f-g) Cladosporium sp., Candida parapsilopsis. Negative initial direct and histopathological examination. (f) Photograph after two months of systemic treatment (total dystrophic onychomycosis). (g) Final photograph after five months of systemic treatment. Clinical cure.

(Fig. 4), Fusarium sp. (Fig. 5), among others), which is probably associated with diabetes-associated immunosuppression (Table 4) [28,29].

In general, greater therapeutic failure was seen in onychomycosis caused by non-dermatophytes molds, followed by yeasts. Although the clinical improvement in these patients, both partial and total, was highly evident and larger than expected, the mycological and histological cure was far below from what was expected, hence we consider that a longer treatment time is required, either with the same medication or with topical and systemic combination therapy, and wait for a new culture and histological study. Approximately 20$25 \%$ of patients do not respond to the initial therapy and often switch to different treatments. An undetermined percentage of patients do not respond to any of the therapies [30]. The non-dermatophyte molds such as Fusarium spp., are the most resistant fungi to standard treatment for onychomycosis either topical or systemic [31], non-responders are defined as those patients who received treatment for six and three months without improvement in more than $50 \%$ of the nail unit $[32,33]$.

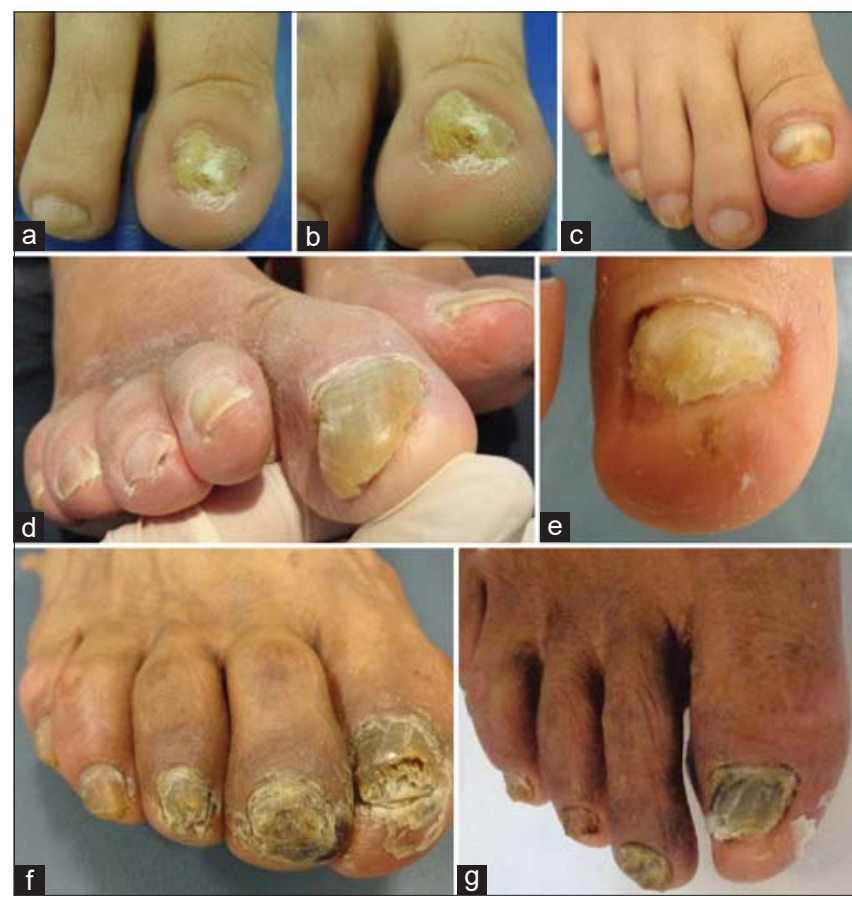

Figure 4: (a-c) Cryptococcus albidus. Positive direct and histopathological examination. (a-b) Photograph at the onset of topical treatment (total dystrophic onychomycosis). (c) After six months of topical treatment. Clinical and mycological cure. (d-e) Fusarium sp. Positive direct examination and histopathological study. (d) Initial photograph (total dystrophic onychomycosis). (e) After five months of systemic treatment with itraconazole $200 \mathrm{mg}$ per day and $40 \%$ topical urea. Clinical and mycological cure. (f-g) Cryptococcus albidus, Cladosporium sp. Positive direct examination. (f) Initial photograph (total dystrophic onychomycosis). (g) Final photograph (one month of systemic treatment with itraconazole in pulses of $400 \mathrm{mg}$ ). $10 \%$ improvement.

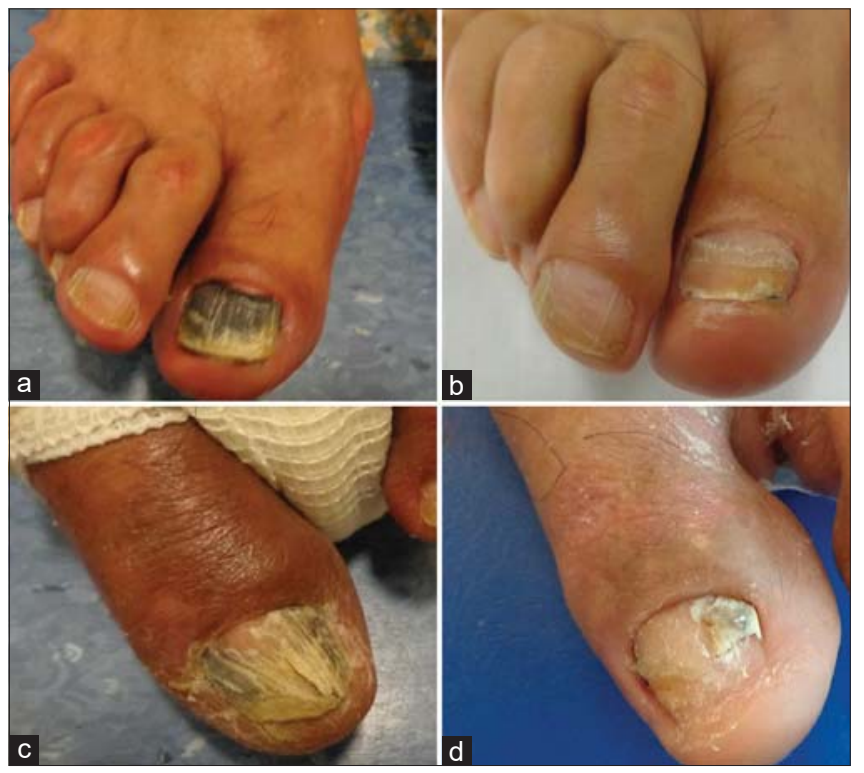

Figure 5: (a-d) Fusarium sp. Negative direct examination. Positive histopathological study. (a) Initial photograph (total dystrophic onychomycosis). (b) After three months of systemic treatment with itraconazole pulses of $400 \mathrm{mg}$ per day and topical urea at $40 \%$ ). Clinical cure without mycological cure. (c) Left foot. (d) Left foot control. 
Table 4: Comparison of culture isolates before and after treatment.

\begin{tabular}{|c|c|c|c|}
\hline & $\begin{array}{l}\text { Isolates } \\
\text { Before } \\
\text { Treatment } \\
(n=26)\end{array}$ & $\begin{array}{c}\text { Mycological } \\
\text { Cure } \\
(n=15)\end{array}$ & $\begin{array}{c}\text { Mycological } \\
\text { Failure After } \\
\text { Treatment } \\
(n=11)\end{array}$ \\
\hline Onychomycosis by yeasts & $9(34.6 \%)$ & $7(46.6 \%)$ & $2(18 \%)$ \\
\hline $\begin{array}{l}\text { Candida sp. } \\
\text { C. albicans }\end{array}$ & $1(3.8 \%)$ & & \\
\hline C. parapsilopsis & $5(19.2 \%)$ & & $2(18 \%)$ \\
\hline C guilliermondi & $3(11.5 \%)$ & & \\
\hline Other yeasts & $4(15.3 \%)$ & $1(6.66 \%)$ & $3(27 \%)$ \\
\hline Rhodotorula sp. & & & \\
\hline Rhodotorula glutini & $1(3.8 \%)$ & & \\
\hline Rhodotorula mucilagi & & & $1(9 \%)$ \\
\hline Cryptococcus albidus & $3(11.5 \%)$ & & \\
\hline Cryptococcus neoformans. & & & $1(9 \%)$ \\
\hline Cryptococcus unigutt. & & & $1(9 \%)$ \\
\hline Filamentous fungi & & & \\
\hline Dermatophytes & $1(3.8 \%)$ & & $1(9 \%)$ \\
\hline Trichophyton sp. & $1(3.8 \%)$ & & $1(9 \%)$ \\
\hline $\begin{array}{l}\text { Non-dermatophytes } \\
\text { Filamentous hyaline fungi: } \\
\text { Acremonium }\end{array}$ & $12(46.15 \%)$ & $7(46.6 \%)$ & $5(45.4 \%)$ \\
\hline Fusarium sp. & $1(3.8 \%)$ & & $1(9 \%)$ \\
\hline Aspergillus sp. & $3(11.5 \%)$ & & $2(18 \%)$ \\
\hline Dematiaceous & $2(7.6 \%)$ & & \\
\hline Alternaria $s p$. & & & \\
\hline Cladosporium sp. & $2(7.6 \%)$ & & \\
\hline $\begin{array}{l}\text { Mucorales (zigomycetous). } \\
\text { Absidia sp. }\end{array}$ & $1(3.8 \%)$ & & $1(9 \%)$ \\
\hline $\begin{array}{l}\text { Epicoccum } s p . \\
\text { Penicillium } s p . \\
\text { Aerobasidium } s p .\end{array}$ & & & \\
\hline Trichoderma sp. & $\begin{array}{l}2(7.6 \%) \\
1(3.8 \%)\end{array}$ & & $1(9 \%)$ \\
\hline
\end{tabular}

It would be worth conducting a study on patients without diabetes mellitus to compare whether it is the immunosuppression of diabetes and its systemic affection as well as the foot abnormalities of the diabetic patient that cause more nail dystrophy, an increased fungal load, and treatment resistance.

Recently, a reproducible and objective system called the Onychomycosis Severity Index (OSI) was created to describe the extent and involvement of distal subungual onychomycosis, with points are given based on the area (\%) of nail involvement, the proximity of the disease to the matrix, and the presence of dermatophytoma or subungual hyperkeratosis [16].

In conclusion, onychomycosis is a common ungual disease that affects a large part of the global population. Its prevalence is increasing, influenced in part by its association with older age, lifestyle, and concomitant diseases. It may cause disability and lead to mild to severe complications, among which the most important is the diabetic foot, which may condition osteomyelitis and sepsis, which justifies its early treatment. In addition, it requires a correct diagnosis, which includes clinical evaluation, direct examination, culture, and a histopathological study, since there are other non-fungal diseases of the nails that resemble onychomycosis and are over-treated, generating expensive treatments with potential adverse effects, which makes it mandatory to confirm the clinical diagnosis with direct examination, culture, and, if possible, histopathological study. The treatment of onychomycosis is one additional facet of diabetic care that promises to further improve outcomes in these patients.

\section{ACKNOWLEDGMENTS}

We would like to thank the ethics committee of the Instituto Nacional de Ciencias Médicas y Nutrición "Salvador Zubirán" for the approval of this study. We would also like to thank the microbiology department of the same institution for the interpretation of cultures and histopathological studies. All the photographs of patients with onychomycosis are published with their approval. The patients in this manuscript gave written informed consent to the publication of their case details. All authors revised the manuscript and provided critical feedbacks. All authors approved the final version of the manuscript for submission. All authors believe that the manuscript represent honest work.

\section{Statement of Human and Animal Rights}

All the procedures followed were in accordance with the ethical standards of the responsible committee on human experimentation (institutional and national) and with the 2008 revision of the Declaration of Helsinki of 1975.

\section{Statement of Informed Consent}

Informed consent for participation in this study was obtained from all patients.

\section{REFERENCES}

1. Lecerf P, Abdy S, Vollono L, Pastushenko I, Richert B, André J. Direct examination, histopathology and fungal culture for the diagnosis of onychomycosis: A retrospective, comparative study on 2245 specimens. Mycoses. 2021;64:187-93.

2. Chang P, Domínguez K. [Nail diseases in elderly. Report of 71 cases]. Our Dermatol Online. 2016;7:385-90.

3. Piraccini BM, Alessandrini A. Onychomycosis: A review. J Fungi (Basel). 2015;1:30-43.

4. Tamer F, Yuksel ME. Onychomycosis due to mixed infection with non-dermatophyte molds and yeasts. Our Dermatol Online. 2019;10:267-9.

5. Dogra S, Kumar B, Bhansali A, Chakrabarty A. Epidemiology of onychomycosis in patients with diabetes mellitus in India. Int J 
Dermatol. 2002;41:647-51.

6. Takehara K, Oe M, Tsunemi Y, Nagase T, Ohashi Y, Iizaka S, et al. Factors associated with presence and severity of toenail onychomycosis in patients with diabetes: A cross-sectional study. Int J Nurs Stud. 2011;48:1101-8.

7. Boyko WL, Doyle JJ, Ryu S, Gause D. Onychomycosis and its impact on secondary infection development in the diabetic population. Presented at the $4^{\text {th }}$ Annual International Meeting of the International Society for Pharmacoeconomics and Outcomes Research (ISPOR), Arlington. VA, 23-26 May.

8. Al-Mutairi N, Eassa BI, Al-Rqobah DA, Clinical and mycologic characteristics of onychomycosis in diabetic patients, Acta Dermatovenerol Croat. 2010;18:84-91.

9. Tamer F, Yuksel ME. Onychomycosis due to Aspergillus niger without black nail discoloration: A case report. Our Dermatol Online. 2017;8:233-4.

10. Cathcart S, Cantrell W, Elewski Be. Onychomycosis and diabetes. J Eur Acad Dermatol Venereol. 2009;23:1119-22.

11. Piraccini BM, Iorizzo M, Lencastre A, Nenoff P, Rigopoulos D. Ciclopirox hydroxypropyl chitosan $(\mathrm{HPCH})$ nail lacquer: A review of its use in onychomycosis. Dermatol Ther (Heidelb) 2020;10:917-29.

12. Gupta AK, Nakrieko KA. Molecular determination of mixed infections of dermatophytes and nondermatophyte molds in individuals with onychomycosis. J Am Podiatr Med Assoc. 2014;104:330-6.

13. Ding CH, Rahman MM, Tzar MN, Yusoff H, Satim H, Nondermatophytic moulds and yeasts as agents of onychomycosis in a Malaysian medical centre. Bangladesh J Med Sci. 2017;16:380-3.

14. Boyko EJ, Ahroni JH, Cohen V, Nelson KM, Heagerty PJ. Prediction of diabetic foot ulcer occurrence using commonly available clinical information: The Seattle Diabetic Foot Study. Diabetes Care 2006;29:1202-7.

15. Akkus G, Evran M, Gungor D, Karakas M, Sert M, Tetiker T, Tinea pedis and onychomycosis frequency in diabetes mellitus patients and diabetic foot ulcers: A cross sectional - Observational study. Pak J Med Sci. 2016;32:891-5.

16. Onalan O, Adar A, Keles H, Ertugrul G, Ozkan N, Aktas H, et al. Onychomycosis is associated with subclinical atherosclerosis in patients with diabetes. Vasa. 2015;44:59-64.

17. Tsuboi R, Mochizuki T, Ito H, Kawano S, Suzuki Y, Naka W, et al. Validation of a lateral flow immunochromatographic assay for tinea unguium diagnosis. J Dermatol. 2021;48:633-637.

18. Bonifaz A, Cruz-Aguilar P, Ponce RM. Onychomycosis by molds. Report of 78 cases. Eur J Dermatol. 2007;17:70-2.

19. Gupta AK, Stec N, Summerbell RC, Shear NH, Piguet V, Tosti A, et al. Onychomycosis: A review. J Eur Acad Dermatol Venereol. 2020;34:1972-90.

20. Reinel D. Non-dermatophyte fungi in onychomycosisEpidemiology and consequences for clinical practice. Mycoses. 2021;64:694-700.

21. Wang Y, Geizhals S, Lipner SR. Retrospective analysis of laboratory abnormalities in patients prescribed terbinafine for onychomycosis.
J Am Acad Dermatol. 2021;84:497-9.

22. Souza AMS, Ribeiro RCA, Pinheiro GKLO, Pinheiro FI, Oliveira WN, Souza LBFC, et al. Polishing the therapy of onychomycosis induced by Candida spp.: Amphotericin B-loaded nail lacquer. Pharmaceutics. 2021;13:784.

23. Shenoy MM, Teerthanath S, Karnaker VK, Girisha BS, Krishna Prasad MS, Pinto J. Comparison of potassium hydroxide mount and mycological culture with histopathologic examination using periodic acid-Schiff staining of the nail clippings in the diagnosis of onychomycosis. Indian J Dermatol Venereol Leprol. 2008;74:226-9.

24. Wilsmann-Theis D, Sareika F, Bieber T, Schmid-Wendtner MH, Wenzel J. New reasons for histopathological nail-clipping examination in the diagnosis of onychomycosis. J Eur Acad Dermatology Venereol. 2011;25:235-7.

25. Cinotti E, Fouilloux B, Perrot JL, Labeille B, Douchet C, Cambazard F, Confocal microcopy for healthy and pathological nail. J Eur Acad Dermatol Venereol. 2014;28: 853-8.

26. Piraccini BM, Alessandrini A. Onychomycosis: A review. J Fungi, 2015;1:30-43.

27. Moreno-Sabater A, Ouali N, Chasset F, Frances C, Senet P, Faucon $\mathrm{C}$, et al, Severe onychomycosis management with oral terbinafine in a kidney transplantation setting: Clinical follow-up by image analysis. Mycoses. 2020;64:309-15.

28. Vlahovic TC. Onychomycosis. Clin Podiatr Med Surg 2016;33:305-18.

29. Bonifaz A, Tirado-Sánchez A, Jaramillo-Manzur C, Araiza J, FierroArias L. Candida balanitis. Clinical and mycological study about the efficacy of a single-day oral treatment with itraconazole $(400 \mathrm{mg})$. Our Dermatol Online. 2020;11:1-5.

30. Shemer A, Trau H, Davidovici B, Grunwald MH, Amichai B. Collection of fungi samples from nails: Comparative study of curettage and drilling techniques. J Eur Acad Dermatology Venereol. 2007;21:1-4.

31. Bonifaz A, Vázquez-González D, Amado S, Fierro-Arias L, PonceOlivera M R. Refractory onychomycosis due to trichophyton rubrum: Combination therapy with itraconazole and terbinafine. N Dermatol Online. 2011;3:108-12.

32. Baudraz-Rosselet F, Ruffieux C, Lurati M, Bontems O, Monod M. Onychomycosis insensitive to systemic terbinafine and azole treatments reveals non-dermatophyte mould as infectious agents. Dermatology 2010;220:164-8.

33. Verrier J, Pronina M, Peter C, Bontems O, Fratti M, Salamin K, et al. Identification of infectious agents in onychomycoses by PCR-terminal restriction fragment length polymorphism. J Clin Microbiol. 2012;50:553-61.

Copyright by Alma lleana Molina-Hernandez, et al. This is an open access article distributed under the terms of the Creative Commons Attribution License, which permits unrestricted use, distribution, and reproduction in any medium, provided the original author and source are credited.

Source of Support: Nil, Conflict of Interest: None declared. 